\title{
As Narrativas do Movimento Negro no Campo Político Brasileiro: do Protesto à Política Institucionalizada
}

\author{
Black Movement's Narrative in the Brazilian Political Field: \\ from Protest to Institutionalized Policy
}

\section{Joana Tereza Vaz de Moura}

Universidade Federal do Rio Grande do Norte, Natal, Rio Grande do Norte, Brasil

\section{Paulo Cesar Ramos}

Universidade de São Paulo, São Paulo, Brasil

\section{RESUMO}

A aprovação do Estatuto da Igualdade Racial, em 2010, representou um avanço no debate das questões raciais no Brasil. As narrativas usadas pelo movimento negro tiveram um papel estratégico nesse processo. Nesse artigo, examinamos as narrativas através das quais o movimento negro se legitimou como um ator político legítimo. Buscamos contribuir para a literatura dos movimentos sociais trazendo as narrativas como estratégias essenciais para pautar demandas e atingir resultados na sua relação com o Poder Público. Utilizamos como fontes de informação entrevistas com representantes do movimento negro e documentos disponíveis. O estudo mostra que os ativistas operaram dentro dos limites discursivos do campo político e aproveitaram as oportunidades políticas sinalizadas pelo Estado, reconhecendo-os e legitimando-os como agentes políticos. Enfatizamos também, as circunstâncias que possibilitaram a unificação de um discurso e a concertação para uma narrativa para que os negros se tornassem protagonistas nesse debate.

Palavras-chave: Narrativas, Movimentos sociais, Política, Estatuto da Igualdade Racial. 


\section{ABSTRACT}

The approval of the Racial Equality Statute, in 2010, represented a step forward in the debate on the racial question in Brazil. The narratives used by the black movement played a strategic role in this process. In this paper, we examine these narratives through which black movement became legitimated as a category of political actor. We try to contribute to social movement theory understanding narratives as a political strategy used to approve their demands. We used with source of information interviews with representatives of the black movement and documents. The study shows that the black activists operates within the discursive boundaries of the political field and political opportunities in whichthe state came to see the movement as a legitimate political category. Following this, we emphasize the circumstances that allowed for a unified discourse for blacks to become the protagonists of the debate.

Keywords: Narratives; Social movement; Politics; Racial Equality Statute.

\section{INTRODUÇÃ̃o}

O movimento negro no Brasil tem se destacado recentemente como um sujeito político importante no processo de democratização, especialmente a partir dos anos 2000. Conforme destaca Paschel (2015), os negros se tornaram legitimados como categoria política importante no país. Esse reconhecimento político possibilitou uma mudança em vários setores do governo, construindo novos processos de elaboração e implementação de políticas públicas, chamadas políticas de Igualdade Racial, dentre as quais, encontramos os Estatuto da Igualdade Racial.

O reconhecimento, notado por Paschel, veio da atuação estratégica dos movimentos na utilização de discursos e narrativas combinada às oportunidades políticas dos contextos políticos, econômicos e sociais. Segundo Gomes (2011, p.135), “esse movimento produz discursos, reordena enunciados, nomeia aspirações difusas ou as articula, possibilitando aos indivíduos que dele fazem parte reconhecerem-se nesses novos significados".

Combina-se a esse processo a criação de uma janela de oportunidade (KINGDON, 2003) a partir de 2003, com a entrada de Luiz Inácio Lula da Silva na Presidência da República. Novos arranjos institucionais de incentivo à participação social, como conselho setoriais de políticas públicas e a realização de conferências participativas (MORAIS, 2016) deram cadência entre as políticas públicas implementadas e o fortalecimento e mesmo surgimento de atores coletivos da sociedade civil (AGUIÃO, 2017). Neste sentido, "movimentos sociais e atores estatais experimentaram criativamente com padrões históricos de interação Estado-sociedade e 
reinterpretaram rotinas de comunicação e negociação de formas inovadoras" (ABERS; SERAFIM; TATAGIBA, 2014, p. 326).

Entendemos que centrar nossa discussão nas narrativas utilizadas pelos movimentos sociais elucida como os ativistas têm usado os discursos estrategicamente como meio de influenciar a agenda pública. Argumentamos que a constituição de uma determinada narrativa pelos movimentos sociais teve como base estratégica a busca por legitimar-se, ressignificar-se e constituir-se como elemento central no campo político. Sendo assim, cabe a nós questionarmos quais foram os elementos constitutivos dessas narrativas pelos ativistas do movimento negro para que conseguissem aprovar, em 2010, o Estatuto da Igualdade Racial, ou seja, como se articularam desde o ano 2000 de maneira a proporcionar que suas demandas fossem reconhecidas e levadas em consideração na cena política. Qual o sentido das narrativas utilizadas pelos sujeitos negros para alcançar seus objetivos e qual é a sociedade que elas revelam, conflitos, consensos e expectativas?

Polletta (2006) ressalta que os grupos em desvantagem na sociedade, sendo muitos os movimentos sociais, por exemplo, podem se beneficiar das narrativas no espaço da disputa política. Mais do que isso, Goodwin, Jasper e Polletta (2001) afirmam a importância da análise das narrativas para alcançar o significado das ações coletivas, e por meio delas compreender a estrutura social. Existe um teor cognitivo nas expressões que denunciam a discriminação, e nas expressões que buscam justiça e igualdade; um conteúdo que fala dos atores, mas também fala da sociedade em que vive. (GOODWIN, JASPER ; POLLETTA, 2001, p. 20).

Partimos da hipótese de que o movimento negro conseguiu construir, ao longo de sua existência, narrativas que possibilitaram que setores da população brasileira se identificassem com as suas demandas e, inclusive, apoiassem as reivindicações no campo político. Nas narrativas expressas pelos diversos atores, estavam as chaves cognitivas que permitiam alianças, solidariedade e legitimidade política (KANE, 2001, p. 251). Essas narrativas foram a base para que muitos parlamentares votassem favorável à aprovação do Estatuto. Este artigo aponta para as histórias construídas pelo movimento negro, ao longo dos últimos anos (ao menos durante o último período democrático), que tiveram um alcance significativo no campo político, possibilitando a entrada da discussão sobre o Estatuto da Igualdade Racial num contexto de um país dominado cultural e politicamente por homens brancos. Saídos de uma dinâmica de denúncia nos anos 1970, nos anos 2000, passa a importar a construção de uma agenda afirmativa de direitos e implementação de políticas públicas com forte interlocução com o Estado.

Tivemos como material de pesquisa o livro Histórias do Movimento Negro no Brasil: depoimentos ao CPDOC (2007), além de jornais, revistas e blogs (Geledés - Instituto da 
Mulher Negra, Mundo Afro, Afropress, Vermelho Portal etc.) que divulgaram entrevistas com lideranças relevantes do movimento negro brasileiro. Também realizamos três entrevistas com militantes que fizeram parte das discussões sobre a construção do projeto de Lei do Estatuto da Igualdade Racial: Jerônimo Silva, representante da União de Negros pela Igualdade-UNEGRO, Thiago Tobias, representante do Educafro, e Deise Benedito, representante do Fala Preta!. Essas entrevistas foram realizadas a partir de um mapeamento inicial de grupos centralmente envolvidos nas discussões sobre o Estatuto da Igualdade Racial.

Importante destacar que os conteúdos das entrevistas não podem ser generalizados para a inteireza da experiência do Movimento Negro e do Estatuto da Igualdade Racial, assim como estas entrevistas não serão representativas de todo o grupo de ativistas que participaram do processo de aprovação do Estatuto. Procuramos selecionar as entrevistas a partir do lugar que cada um/uma ocupa no campo do diverso movimento social negro, assim como pela viabilidade da entrevista e acessibilidade. Procuramos trazer para a análise um interlocutor sem qualquer ligação partidária, uma interlocutora do chamado movimento de mulheres negras, e um interlocutor com relações diretas com organizações que indicaram membros para a composição de governo federal, no caso, a Unegro para a SEPPIR.O estudo não se propõe, assim, a ater-se às principais narrativas identificadas nas entrevistas e na pesquisa documental.

O texto está dividido em quatro partes fundamentais, além desta introdução. Na primeira parte, discutimos o potencial analítico da literatura sobre narrativas e movimentos sociais para construir uma agenda de demandas específicas no campo político brasileiro. Na segunda parte, analisamos as narrativas utilizadas pelo movimento negro para a sua ressignificação às formas como a história foi tradicionalmente contada. No item três, mostramos como, dentro do próprio movimento negro, foram se constituindo narrativas divergentes à várias pautas propostas no Estatuto. No quarto item, apresentamos a narrativa que marcou o processo da obtenção de apoio à aprovação do Estatuto, uma vez que o movimento negro já tinha um papel político importante nesse processo e, portanto, os ativistas usaram histórias estrategicamente para obter apoio e fazer reivindicações em diversos contextos (POLLETTA, 2013). Por fim, apresentamos as considerações finais. 


\section{NARRATIVAS COMO ESTRATÉGIAS DE CONSTRUÇÃO DAS MOBILIZAÇOEES E PERSUASÃO}

A utilização da narrativa como aparato teórico-metodológico permite aos estudiosos dos movimentos sociais conhecer o contexto social em que as ações transcorrem. Além disso, faz parte de uma estratégia utilizada pelos movimentos sociais buscando legitimar-se, ressignificar-se e constituir-se como elemento central no campo político. Cabe, então, questionar quais são os argumentos utilizados pelo movimento negro para que interesses coincidam e os argumentos sejam levados em consideração na cena política.

Buscamos entender a complexidade dos movimentos sociais enquanto organizações que se movem no campo político permeados por questões culturais e aspectos estruturais, organizados nas relações entre estrutura social formal e informal. Como destacam Armstrong e Bernstein (2008), a cultura é constitutiva dos aspectos estruturais, portanto a definição e uso do conceito de oportunidades políticas não pode ser entendido sem relacioná-lo à cultura, identidade e estrutura dos movimentos sociais.

As narrativas, assim, são recursos essenciais dos ativistas que procuram através delas mobilizar mais pessoas, trazer apoiadores, influenciar decisões políticas e manter as ações dos movimentos (POLLETTA; GARDNER, 2015).

Interessada em discutir a capacidade das narrativas em modificar as estruturas sociais, Polletta busca entender as histórias contadas por atores coletivos e como são utilizadas como ações estratégicas dos movimentos sociais. Neste sentido, existe um poder das narrativas que requer esclarecimentos pela teoria dos movimentos sociais. Para Polletta (2006, p. 05), "esses são processos que continuam mal compreendidos pelos sociólogos dos movimentos sociais".

Retomando a perspectiva cultural dos movimentos sociais, Polleta sustenta que o aspecto cultural define e reforça a construção de interesses e, portanto, as estratégias a serem utilizadas, mas vai além disso apontando para as condições estruturais em que esses aspectos são redefinidos. Sendo assim, o campo de estudos dos movimentos sociais deve envolver discussões sobre a importância da cultura e das estruturas sociais.

Segundo Jimeno (2016, p.17), as análises de narrativas devem incluir ao menos dois contextos sociais: o que marca a experiência social dos sujeitos que produziram a narrativa e os contextos de uso dessas narrativas produzidas. A importância do posicionamento conjuntural dos sujeitos que contam a história demonstra que existe um domínio de como eles veem o mundo, ou conforme já apontava Bourdieu (2004), não isolar a linguagem de suas condições 
sociais de produção. Neste caso,

[...] a ciência social deve tomar como objeto não apenas essa realidade, mas também a percepção dessa realidade, as perspectivas, os pontos de vista que, em função da posição que ocupam no espaço social objetivo, os agentes têm sobre essa realidade (BOURDIEU, 2004, p. 157).

Destacamos que a utilização de narrativas pelos movimentos sociais é uma estratégia que busca mobilizar participantes, agregar aliados e ao final influenciar a decisão política. As narrativas, portanto, fazem parte da dimensão cultural dos movimentos sociais. Segundo Coley (2015), deveríamos entender as narrativas enquanto meios capazes de potencializar o envolvimento de atores em movimentos sociais. Os enredos, personagens e a moral das narrativas incentivam os leitores para a ação coletiva, especialmente os personagens que seriam os agentes simbólicos. A maneira como os personagens são descritos e as suas relações com outros atores fortalece as mensagens de como entender a dinâmica das mobilizações e sobre a coletividade que eles representam (ISAAC, 2008 apud COLEY, 2015).

Neste sentido, acreditamos que as ideias passadas através das narrativas presentes na atuação do movimento negro foram essenciais para a construção e consolidação de interesses coletivos que se agregaram ao histórico de mobilização, tendo, dessa forma, culminado na aprovação do Estatuto. Especialmente a incessante luta do movimento contra o racismo presente na sociedade brasileira.

Importa fazer este registro em termos de pesquisa social, uma vez que o processo analisado nestas páginas contrasta com os dias que correm quando elas estão sendo escritas. Aquilo sobre o que os autores escrevem desenha uma curva ascendente de ganhos democráticos e de interação construtiva entre Estado e sociedade civil; o Estatuto da Igualdade Racial, com todos os seus problemas e vazios, chegou na mesma esteira de uma série de outros direitos, como a Lei que criminaliza a violência contra as mulheres, ou a política de aumento de salário mínimo. Contudo, desde 2016, o Estado brasileiro passa a dar sérios sinais de que ativismos de diversos matizes, além de não serem bem-vindos na construção da nação, também poderão ser criminalizados caso alguma autoridade assim o creia. Sendo até mesmo a atividade de pesquisa um problema aos olhos de quem nos governa. 


\section{AS HISTÓRIAS CONTADAS PELO MOVIMENTO NEGRO: ENREDO, PERSONAGENS E SEQUEENCIA CAUSAL}

As narrativas que apresentadas ao longo dos anos pelo movimento negro brasileiro tiveram a finalidade de reconstruir a história dos negros, buscando fortalecer identidades, apresentar interesses, e explicitar as dinâmicas da ação coletiva. Apresentamos a narrativa contada pelas lideranças do movimento sobre o processo histórico de luta dos negros no Brasil e as motivações para a mobilização. Tais narrativas ocupam muitas vezes histórias de memórias de cunho privado, como histórias da infância, histórias de discriminação no mundo do trabalho, mas também aquelas iniquidades apresentadas no mundo da política ou então, a construção de um entendimento coletivo por meio de dinâmicas próprias de movimentos sociais.

A experiência que nos é reportada conta uma história de sair da denúncia da discriminação racial e do empreendimento da desmistificação da democracia racial para um outro cenário de afirmação de identidade e de busca por concretizar direitos. Esta passagem culmina na construção de políticas públicas e na aprovação do Estatuto da Igualdade Racial como um marco legal destas políticas.

Segundo Gomes (2007, p. 5), "a luta pela afirmação do negro no Brasil tem tradição e passado, com iniciativas que remontam à Primeira República”. O movimento negro redescobre “os significados políticos de memórias da escravidão" (GOMES, 2007, p. 7) e constrói sua própria história e do que é ser negro no contexto brasileiro, enunciando nos termos da narrativa os significados dos problemas, das vivências e da transformação necessária e sua agenda política.

O questionamento sobre a história contada pelos livros didáticos no Brasil aparece na fala de Ivair Alves dos Santos, fundador, no governo paulista de Franco Montoro (1983-1987), do Conselho de Participação e Desenvolvimento da Comunidade Negra, em entrevista ao CPDOC:

[...] na época, os livros didáticos tinham aquelas fotografias de negro apanhando, não é? Aí um dia eu perguntei: "Mas por que eles só apanham? Não tem outra coisa que eles fazem a não ser apanhar?" E eles argumentavam que não era só aquilo. Mas é que me incomodava aquele processo. (ALBERTI; PEREIRA, 2007, p.64).

Percebemos a inquietação já presente desde cedo na vida de muitos militantes, por vezes sustentada pela indignação dos pais, muitos deles também militantes desde jovens.

Influenciados pela movimentação norte-americana, vários militantes do movimento ne- 
gro contam que as manifestações dos negros nos Estados Unidos foram as primeiras referências de identificação que eles tiveram, conjuntamente com as lutas pela independência no continente africano. Conforme relata Gilberto Leal, militante da CONEN, em entrevista à Alberti e Pereira (2007, p.66): "Então, o movimento negro, seu pensamento de afro brasilidade, formou-se muito com referência em algumas lideranças negras americanas e em países da linha de frente nos processos de libertação africana".

Havia muitas leituras sendo feitas pelos militantes da época na tentativa de construção de um movimento sólido. Conforme destaca Hédio Silva Júnior:

A gente lia muito, qualquer coisa (...) e o Ivair nessa época morava em África e mandava jornais e livros para algumas pessoas (...) O que surgisse no grupo a gente lia e discutia. Então era uma compilação, porque você estava lendo sobre a experiência das lutas independentes em África lusófona (...). Enfim, tudo que pintasse de preto, de racismo, a gente lia. (ALBERTI; PEREIRA, 2007, p. 68).

Carlos Alberto Medeiros, coordenador da CONEN, também comenta sobre as inspirações dessas lutas na África e nos Estados Unidos para o movimento negro brasileiro. "Tínhamos muita inspiração tanto na luta na África, quanto na luta nos Estados Unidos. Como é que a gente traduziria aquilo, como é que a gente pegaria as informações interessantes daquilo?" (ALBERTI; PEREIRA, 2007, p.72).

Então, consideramos que essa movimentação de trocas possibilitou a pavimentação de um espaço de compartilhamento de referências, donde emergiu a identidade de uma geração de militantes negros no Brasil, no pós Regime Militar, que era consolidada cada vez mais pelas narrativas dos ativistas, influenciados pelas histórias contadas nos EUA e na África, com uma identidade negra transnacional (HANCHARD, 2001). Vários ativistas produziram discursos que enfatizavam as histórias de Martin Luther King e Malcom X para explicar à população o porquê da criação de organizações que lutavam pelos direitos dos negros. Esses personagens vão se tornar as grandes referências para os ativistas brasileiros, que passam a se identificar com suas atuações e explicitam a moral dessas lutas, possibilitando a criação de narrativas próprias no contexto brasileiro. Conforme Coley (2015) destacou, os personagens seriam os agentes simbólicos que, no imaginário das pessoas, reforçariam a luta antirracista promovendo adesões e influenciando a luta política.

Os militantes buscavam valorizar a história africana porque, a partir dela, recontariam a história brasileira, conforme destaca Carlos Alberto Medeiros:

(...) a valorização da histórica africana, que era uma coisa que valia lá na 
África e também nos Estados Unidos e também era válida aqui. Aqui a gente poderia acrescentar a história afro-brasileira, adaptar essa ideia e trazer isso pra cá. Isso era absolutamente válido e necessário. A valorização de uma estética negra. Isso era coisa que cabia (...). (ALBERTI; PEREIRA, 2007, p. 73).

A exaltação da cultura africana desempenhando um papel crucial na politização e conscientização racial. Hely Pedreira, ativista e professora de áreas quilombolas, destaca o papel da cultura: "Com certeza a questão cultural é um aliado de muito peso, pois traduz a questão identitária dos sujeitos e suas representações”, afirma. (GELEDÉS, 2017).

A Marcha contra a Farsa da Abolição, em 1988, simbolizou um marco nas mobilizações do movimento negro. Um protesto que reuniu mais de 5 mil pessoas, cujo objetivo era explicitar uma posição crítica acerca das comemorações do centenário da abolição da escravidão.

Os discursos da grande mídia giravam em torno dos grandes eventos que aconteceriam naquele momento celebrando a abolição. Por outro lado, o movimento negro, pautava um discurso de protesto e que buscava questionar o processo de abolição e demarcar o racismo existente na sociedade brasileira. Nas opiniões de Amauri Mendes e Sueli Carneiro, a Marcha e o centenário da abolição foram momentos essenciais para a luta política:

A Marcha contra a Farsa da Abolição, de 1988, no Rio de Janeiro, foi realmente um momento que somou uma determinação com uma consciência do que a gente estava fazendo, de que era preciso romper com aquela visão quase idílica que todos os órgãos de divulgação colocavam do centenário da Abolição. A Globo começou o ano com aquele "axé da Globo", vocês lembram? (...) Todos os artistas negros conhecidos da Globo e alguns que não eram da Globo, outros negros que eram conhecidos (...) vinham e davam seu "axé". (...) Todos os jornais, logo no início do ano, fizeram cadernos especiais sobre isso. Cadernos do Estadão, da Folha de S. Paulo, de dez páginas, 20 páginas, às vezes sobre arte, às vezes sobre o negro na situação atual, variava muito o lugar. (...) Mas tudo era uma forma de ver harmonia. E nós estávamos ali exatamente para botar água nessa sopa. Era para mostrar que não havia harmonia. Nosso ímpeto era mostrar que havia o contrário, havia o racismo... (ALBERTI; PEREIRA, 2007, p. 212).

Eu acho que em 1988 o movimento negro brasileiro deu a resposta adequada ao Estado brasileiro, às tentativas de manipular o sentido do centenário da Abolição. Aquilo que a gente havia anos atrás definido como uma data de denúncia, acho que a gente fez isso cabalmente no ano do centenário. (ALBERTI; PEREIRA, 2007, p. 208).

O simbolismo da Marcha Zumbi, que continuou acontecendo, resultou na consagração 
do movimento negro como ator político nos anos posteriores ${ }^{1}$. Na opinião de Sueli Carneiro:

Foi o fato político mais importante do movimento negro contemporâneo. Acho que foi um momento também emblemático, em que nós voltamos para as ruas com uma agenda crítica muito grande e com palavras de ordem muito precisas que expressavam a nossa reivindicação de políticas públicas que fossem capazes de alterar as concepções de vida da nossa gente. Foi um processo rico, extraordinário. (ALBERTI; PEREIRA, 2007, p. 345).

Nota-se, também, a criação de uma onda de organizações do movimento, especialmente a constituição de coletivos de mulheres negras, que diversificará o repertório discursivo, inserindo a pauta do gênero e sexualidade e rompendo com o mito da rainha do lar e da musa idolatrada dos poetas. Sueli Carneiro, fundadora do Geledés, apresenta a versão do movimento negro feminista sobre a realidade das mulheres negras no país:

As mulheres negras fazem parte de um contingente de mulheres que não são rainhas de nada, que são retratadas como as anti-musas da sociedade brasileira, porque o modelo estético de mulher é a mulher branca. (...) Fazemos parte de um contingente de mulheres para as quais os anúncios de emprego destinam a seguinte frase: "Exige-se boa aparência". (...) Fazemos parte de um contingente de mulheres originárias de uma cultura que não tem Adão. Originária de uma cultura violada, folclorizada e marginalizada, tratada como coisa primitiva, coisa do diabo, este também um alienígena para a nossa cultura. Fazemos parte de um contingente de mulheres ignoradas pelo sistema de saúde na sua especificidade, porque o mito da democracia racial presente em todos nós torna desnecessária a coleta da cor dos pacientes nos formulários da rede de saúde, informação que seria indispensável para avaliarmos as condições de saúde das mulheres negras no Brasil, pois sabemos, por dados de outros países, que as mulheres brancas e negras apresentam diferenças significativas em termos de saúde. As mulheres negras advêm de uma experiência histórica diferenciada, e o discurso clássico sobre a opressão da mulher não dá conta da diferença qualitativa da opressão sofrida pelas mulheres negras e o efeito que ela teve e tem ainda na identidade das mulheres negras (CARNEIRO, 1993, p.11, itálico nosso).

Essa fala mostra como a ênfase na história diferenciada vai sendo utilizada para recrutar novos participantes, manter solidariedade e buscar apoios. As mulheres negras que se inserem nessa luta têm confiança em quem está narrando, especialmente porque conta a história do

1 Em um documentário produzido pela Organização da Marcha Zumbi dos Palmares - 1995, realizada em Brasília, em alusão aos 300 anos da morte de Zumbi, a história é recontada do ponto de vista da escravidão do negro no Brasil. Disponível em: https://www.geledes.org.br/marcha-zumbi-dos-palmares-1995/?gclid=Cj0KCQjwzIzWBRDnARIsAAkc8hHLBSwASx0_zder2L-6fgmgaA33cbw5WLGuNKzxXNVjNL3-W7NFlzkaAsjXEALw_ wcB. 
coletivo evidenciando as questões de gênero, ajudando a construir uma identidade baseada no reconhecimento dessa diferença.

Essas manifestações marcaram o retorno da luta política dos negros no campo político brasileiro e que até hoje se alastram também nos espaços institucionalizados, ganhando força na luta com o poder público e recontando histórias que condizem com os significados das mobilizações do movimento. "No tempo presente, luta-se pela narrativa do passado, recontada para legitimar as pautas de reivindicações sociais postas na cena pública” (RIOS, 2012, p.44). Esse recontar insere-se na lógica do reordenamento dos significados, que vão produzir novas identidades e mobilizar outros atores. São histórias que mexem com as emoções e os sentimentos (RIOS, 2012).

Essa recriação dos símbolos torna-se uma fonte de sustentação do movimento em todo o Brasil, seja através da música (black soul), seja pela afirmação das religiões de matriz africana. "Como sujeito político, esse movimento produz discursos, reordena enunciados, nomeia aspirações difusas ou as articula, possibilitando aos indivíduos que dele fazem parte reconhecerem-se nesses novos significados". (GOMES, 2011, p. 44). Mais que isso, "ao articularem uma identidade, os movimentos sociais acionam símbolos cujos significados são recriados com o fim de expressar pertencimentos e garantir a transmissão de valores e convenções de comportamento" (BARCELOS, 1996, p. 201).

Alguns ativistas entrevistados por Paschel (2015), consideraram a Conferência de Durban como um divisor de águas na luta pela igualdade racial, uma vez que foi após a Conferência que o então presidente Fernando Henrique Cardoso anunciou algumas políticas de ação afirmativa $^{2}$. Entretanto, dois outros fatos têm igual ou maior importância, sendo um deles a Marcha Zumbi, Contra o Racismo, Pela Igualdade e a Vida, de 20 de novembro de 1995, que fez FHC reconhecer publicamente a existência do racismo na sociedade brasileira e criar o Grupo de Trabalho Interministerial para pensar políticas públicas para a população negra. Outro fato que contesta a importância de Durban é, que somente a partir do Governo Lula, as demandas foram sendo reconhecidas com maior peso no aparato institucional.

Isso retroalimentou-se da ocupação de cargos comissionados e pastas de secretarias específicas pelo movimento negro, buscando alterar os rumos das políticas públicas e as formas de implementação, além de várias conferências realizadas que legitimaram as demandas do movimento negro. Um dos resultados dessa participação foi o surgimento de uma dinâmica de

2 "Embora seja possível afirmar que no governo Fernando Henrique Cardoso já havia iniciativas federais voltadas à população negra, a análise dos documentos do período revela que a estratégia discursiva e a política deste governo foi promover o reconhecimento sem investimentos no aspecto redistributivo" (LIMA, 2010, p. 81). 
ação simbólica na qual as diversas organizações do movimento negro se mobilizaram massivamente para demonstrar o poder e legitimidade das demandas por políticas públicas específicas para a população negra e o grau de contentamento ou descontentamento com a ação estatal no que se referia à discussão sobre o Estatuto. "Foi uma caminhada longa, foi um aprendizado para todo mundo" (Deise Benedito, do Fala Preta!, entrevista realizada em abril, 2018).

\section{DISSONÂNCIAS E DISPUTAS NARRATIVAS SOBRE O MOVIMENTO NEGRO}

O Estatuto da Igualdade Racial, aprovado em 2010, não conta com grandes conquistas para o povo negro brasileiro e por isso não deveria ser aprovado, para alguns militantes. Para outros, o EIR, mesmo em sua versão desidratada é um marco para as conquistas. Mais do que o aquilo que o documento diz, a narrativa compõe o seu debate e demarca um conjunto de contradições e consensos da ação coletiva que extrapola o âmbito do Estado, trazendo à baila o conjunto da experiência negra no Brasil, seus problemas, demandas e direitos.

As dissonâncias narrativas em torno do que veio a ser o EIR projetam a diversidade de projetos políticos e ideológicos sobre o que deve ser o compromisso do Estado para com o povo negro, mas também nos apresentam, no léxico mobilizado por cada grupo ao exporem suas razões por aceite ou contrariedade ao texto aprovado, seu entendimento da luta antirracista. De um polo a outro das posições aqui elencadas, conforma-se um espaço em que a luta ganha legitimidade.

"É hora de perguntarmos publicamente aos parlamentares e setores do movimento negro que participam do processo de negociação: qual é o limite da negociação do projeto do Estatuto da Igualdade Racial?" (ROLAND, 2009). Com essa frase dita por Edna Roland, em um artigo publicado no Geledés, começamos esse item buscando entender as narrativas elaboradas pelo movimento que foram responsáveis pela criação de espaços para os acordos e negociações para a aprovação do Estatuto da Igualdade Racial, em 2010.

Segundo Deise Benedito, em entrevista, tiveram muitas pessoas que se opuseram à criação do Estatuto, "não foi uma coisa tão simples e tão fácil de ser criado". No campo do movimento negro, várias organizações se posicionaram de diferentes maneiras, visto que ocorreram modificações substanciais da sua proposta original. As modificações feitas pelo senador Demóstenes Torres (DEM-GO) criaram indignações de lideranças e organizações negras, pois 
várias demandas foram retiradas do documento final, como por exemplo, artigos que criavam as cotas nas universidades públicas, no sistema de serviço público e nos partidos políticos; a política pública de saúde exclusiva para negros, além da retirada do texto de expressões como "fortalecer a identidade negra".

O próprio Edson Cardoso ao ser questionado pelo Geledés ${ }^{3}$ sobre a proposta de projeto apontou para o fracasso de um Estatuto que reduz uma série de artigos que poderiam transformar a vida da população negra do país. Conforme Cardoso:

Que avaliação se pode fazer de uma proposta de legislação que, a rigor, não muda nada na vida das pessoas? Se DEM, PMDB, PSDB, etc., estão felizes com a proposta é razoável nada esperar dela que possa efetiva e concretamente beneficiar a população negra. $(2009$, n. p.).

No Blog Mundo Afro, de acordo com o deputado federal Luiz Alberto (PT-BA), "o Estatuto foi completamente mutilado. As alterações inviabilizaram a proposta, fazer emendas ou alterações será bem mais difícil”. Com a mesma percepção, o membro da direção do Coordenação Nacional de Entidades Negras (CONEN), Gilberto Leal, disse que era difícil entender como o governo negociou com alguém como o senador Demóstenes Torres.

Somos a favor do Estatuto, mas contra as alterações feitas por Demóstenes Torres. Foi ele que disse durante a audiência sobre as cotas no STF que o que foi estupro cometido contra mulheres negras durante a escravidão era na verdade relação consensual. Como uma pessoa dessas tem sensibilidade para legislar sobre uma matéria tão importante? (MUNDO AFRO, 2010, n. p.).

Para Frei Davi dos Santos, da Educafro ${ }^{5}$, a versão do Estatuto como foi aprovada não modifica as desigualdades sociais no país, uma vez que não mexe com o racismo institucional. "O estatuto era e é a compensação por 380 anos de escravidão negra no Brasil. Mas o texto final é quase totalmente sem compromisso, devido às mudanças realizadas na Câmara e no Senado".

Uns dias após a aprovação do Estatuto, vários militantes fizeram uma mobilização na Câmara dos Deputados mostrando a indignação com a retiradas de várias ações na redação final. Reginaldo Bispo, coordenador nacional do Movimento Negro Unificado (MNU), afirmou

3 Entrevista reproduzida pelo site do Geledés, em 28/10/2009.

4 MUNDO AFRO. Estatuto é aprovado com as modificações. 16/06/2010. Disponível em: http://mundoafro.atarde.uol.com.br/tag/gilberto-leal/.

5 Entrevista para a Rede Brasil Atual, em 20/07/2015. Disponível em: http://www.redebrasilatual.com.br/cidadania/2015/07/estatuto-da-igualdade-racial-precisa-de-reformulacao-defendem-militantes-negros-9945.html. 
em entrevista à Rede Brasil Atual ${ }^{6}$, que o texto foi mal discutido pelas organizações do Movimento Negro brasileiro. Segundo ele, "a maioria das pessoas negras, em especial a militância, não conhece nenhum dos textos que circularam até agora".

No portal do Geledés, Reginaldo Bispo reforça a falta de entendimento entre setores do movimento negro. Segundo ele, um grupo composto por representantes da SEPPIR e UNEGRO aceitaram o estatuto conforme modificações do DEM. Para ele:

\begin{abstract}
A UNEGRO e o PCdoB (...) são contrários a Reparação e a Construção de um Projeto Político do Povo Negro para o Brasil. Todos esses setores estão satisfeitos com a democracia parlamentar representativa do faz de contas, que nos pedem que confiemos neles, para lhe darmos cheques em branco, para que falem e decidam em nosso nome. Creem que depois esqueçamos as negociatas que fazem em nosso nome, e de novo os sufraguemos nessas eleições.
\end{abstract}

Em 27 de junho de 2007, Reginaldo Bispo, enquanto coordenador do MNU, escreveu em sua página do Facebook "Estatuto mané, o negro não quer", dirigindo-se ao conjunto da população negra. Nesse texto, o MNU faz uma série de análises sobre a aprovação do Estatuto, ressaltando essencialmente a falta de discussão com a população negra e a retirada de partes essenciais no documento final.

,O Estatuto peca por ter sido fruto de pouca discussão com a população negra,
apenas 9 ou 10 audiências públicas, (...) O presente projeto, que perambulou
pela Câmara e pelo Senado durante anos, não é o projeto original do então
deputado, hoje Senador Paulo Paim. Trata-se de um substitutivo do Senador
Tourinho, representante dos interesses econômico das oligarquias, sem
nenhum vínculo com os interesses populares no Congresso Nacional.

Matilde Ribeiro, militante e ex-ministra da SEPPIR no Governo Lula (2003-2008), também desaprovou fortemente o estatuto conforme sua redação final, especialmente porque retira-se a discussão sobre as cotas raciais. Para ela, "o centro do Estatuto são as ações afirmativas para a população negra. Da forma como foi agora, esse centro foi comprometido. O esqueleto se mantém, mas não faz sentido a aprovação do Estatuto sem as cotas"?.

Thiago Tobias também comenta a aprovação do Estatuto mostrando que houve uma pressão para que Paim levasse adiante o documento, mesmo que com as retiradas dos artigos

6 Entrevista em 30/06/2010. Disponível em: http://www.redebrasilatual.com.br/cidadania/2010/06/militantes-pedem-veto-de-estatuto-da-igualdade-racial.

7 Entrevista concedida para a Afropress, em 07/07/2010, e reproduzida por http://diegomonsalvo.blogspot.com. br/2010/07/sem-cotas-estatuto-da-igualdade-racial.html. 
principais. Segundo Thiago, "estava perto da campanha, os caras queriam aprovar o Estatuto e o pessoal do movimento negro lá, e sentou com o Paim, "vamos aprovar". Aí ele falou, quem sou eu pra poder ficar segurando. Se querem aprovar, então aprova. Acho que tinha que avançar, mas...".

Percebemos, então, que parte do movimento não apresentava forte oposição a que o documento fosse para a aprovação final, entretanto, outra parte do movimento que tinha uma relação mais próxima com o poder público fez pressão para que o senador levasse ao plenário para a aprovação.

Esses queriam a aprovação a despeito das inconsistências apontados por múltiplos setores do movimento negro. Mesmo que decepcionados com o resultado final do documento, acreditam que foi um avanço na luta dos negros no Brasil. Mostrando as divergências dentro do próprio movimento, um outro dirigente da CONEN, Flávio Jorge, em entrevista ao portal G1 ${ }^{8}$, afirma que, "embora o Estatuto não seja exatamente o que a entidade deseja, significa o coroamento de uma luta que o movimento negro tem desenvolvido na construção de políticas públicas e superação do racismo. Passa a ser um marco desses 30 anos de luta”.

$\mathrm{Na}$ época da aprovação do Estatuto, o então coordenador geral da UNEGRO, Edson França ${ }^{9}$, comentou que o Estatuto representava um marco para o movimento negro no Brasil. Para ele, o Estatuto "consolida um novo paradigma de enfrentamento ao racismo, correspondendo a uma correta definição do seu significado". Destaca ainda as dificuldades enfrentadas pelo movimento para a aprovação do Estatuto, uma vez que vários parlamentares já se mostravam desfavoráveis a qualquer modificação no contexto social do país. Segundo ele:

(...) o processo de negociação da redação final do Estatuto da Igualdade Racial durou dez anos, estavam em confronto diversas posições sobre como enfrentar o racismo, projetos de poder, interesses de classes, de segmentos econômicos, concepções culturais, religiosas, filosóficas, etc. (2010, n. p.).

Diante desse contexto, o ativista reconhece que a supressão de determinadas questões foi um problema, mas que isso já era previsto pela SEPPIR e pelo próprio movimento. Por isso, ele destaca que a estratégia utilizada pela Secretaria de "apresentar uma redação com bastante gordura" foi interessante pois sabiam dos possíveis cortes. Ele ainda complementa que:

0 8Disponível em: <http://g1.globo.com/Noticias/Brasil/0,,MUL1301785-5598,00- ESTATUTO+DA+IGUALDADE+RACIAL+DIVIDE+MOVIMENTO+NEGRO.html $>$

9 Entrevista concedida ao Portal CTB, em 17 de agosto de 2010. Disponível em: http://www.portalctb.org.br/ site/estaduais/norte/amazonas/entrevistas/estatuto-da-igualdade-racial-para-unegro-um-grande-passo-para-o-movimento-afro-brasileiro.. 
(...) conquistamos uma lei com 64 artigos estabelecendo direitos, princípios, diretrizes e políticas públicas para promoção social da população negra. Considero que as cotas estão contempladas na instituição da obrigatoriedade de o Estado instituir ações afirmativas na educação, no trabalho, na comunicação. Entendemos que uma boa leitura e correta interpretação do Estatuto, verificaremos a manutenção das principais bandeiras do movimento negro, demonstrando a habilidade dos negociadores e o acerto da tática adotada. (2010, n. p.).

Para Jerônimo da Silva Júnior, também da UNEGRO, o Estatuto não é o ideal, mas é um marco regulatório para as políticas públicas de combate à desigualdade. "Tivemos algumas conquistas e podemos nos mobilizar pra buscar outras durante a próxima legislatura". (MUNDO AFRO, 2010). Em entrevista, ele destaca que o arcabouço do Estatuto tem a ver com as relações entre movimento e Estado. Do seu ponto de vista, não se cria políticas públicas sem a participação do Estado e, portanto, o jogo de interesses e os conflitos são inerentes a esse processo. Destaca que, "apesar do Estatuto não ser impositivo, foi uma conquista do movimento. Não podemos negar que é um avanço para o movimento negro. Dentro da correlação de forças foi uma vitória".

Ainda no Blog Mundo Afro, Alexandre Reis, secretário de Políticas para as Comunidades Tradicionais da SEPPIR, também comenta o resultado final. Segundo ele: "Não é o ideal, mas ele tem ganhos importantes como assegurar o financiamento por parte da União, Estados e municípios para políticas de promoção da igualdade".

Portanto, a grosso modo, podemos identificar dois argumentos expressos no debate político em torno do estatuto à época de sua aprovação, qual seja, "precisamos de um Estatuto, seja ele qual for" versus "este estatuto não serve para nada". Existem dois sentidos para o Estatuto, um que procura criar marcos simbólicos, mas também institucionais, que é a aprovação de um documento que ao menos tematize a questão racial e dê alguma abertura para a conquista de outros direitos; e outro sentido que é a exigência de garantias imediatas, que o próprio estatuto seja a política pública.

Destacam-se entre estas dissonantes vozes presentes no movimento negro as alianças que foram feitas no Parlamento para a aprovação do EIR, que envolveram agrupamentos políticos partidários à direita do espectro político, cujo histórico de posicionamento havia sido contrário aos direitos da população negra, fato que leva militantes a desacreditarem o potencial da versão aprovada. A ausência de políticas de reparação histórica para a população negra é outro ponto que afasta a simpatia de organizações como o MNU, e a ausência da exigência de política de cotas, ou de uma política assertiva para a titulação de terras quilombolas.

Contudo, a aprovação do Estatuto, ela própria se converte em símbolo mesmo na fala de 
uma das lideranças do movimento negro, pois seria o estatuto uma coroação da luta histórica do movimento negro. Tal luta histórica do movimento negro tem seu marco no processo de abertura política, no final dos anos 1970, com a organização do Movimento Unificado contra a discriminação Racial - posteriormente convertido em Movimento Negro Unificado. Ali, e desde então, militantes negros e não negros engajaram-se na denúncia e desconstrução do mito da democracia racial.

A concretude desta missão histórica seria passar a mostrar a necessidade de falar de raça, de racismo, de desigualdade racial, em todas as esferas sociais e colocar a população negra no centro do debate político institucional. Por mais que um dos lados tenha se sobreposto ao outro, o fato de o debate político sobre raça e racismo ter continuado e se ampliado, permitiu que esta disputa entre visões sobre a tarefa do movimento e o papel do Estado fossem representadas em outras arenas. Assim, o EIR, a despeito de não prescrever as receitas necessárias para combater o mal do racismo, estabelece que este seria um problema a ser combatido; e por meio da ação direta do Estado, ou seja, por meio de políticas públicas.

Este teor revela que as políticas públicas ocupam um lugar importante na narrativa de legitimação da luta negra durante o período de democratização. É ela um símbolo da desconstrução do mito na democracia racial por meio Estatal, e o EIR vem ser o veículo deste significado, estabelecendo em seus termos a busca por Igualdade e, em sua substância, a promessa de políticas públicas. É só por esta polarização, mito-democracia racial versus políticas públicas, que o EIR em sua versão final angariou o apoio de militantes negros, e não pelo que ele oferece em si mesmo como solução para os problemas da população negra.

\section{COMO AS NARRATIVAS SÃO ADOTADAS PELOS ATORES POLIITICOS EM DEFESA DO ESTATUTO}

A proposição de um Estatuto da Igualdade Racial aparece nitidamente como resultado de mobilizações históricas no campo das políticas públicas do movimento negro brasileiro. Diferentemente da posição denuncista, importa agora afirmar direitos e buscar a Igualdade Racial por meio de políticas públicas. De acordo com o livro organizado pelo INESC (SANTOS, SANTOS ; BERTÚLIO, 2011), a proposta formal do Estatuto foi apresentada pelo então senador Paulo Paim (PT/RS), em 2010, agregando várias outras proposições já sugeridas por outros parlamentares, como por exemplo o ex-deputado federal e ex-senador Abdias do Nascimento. 
Jerônimo Silva, representante da UNEGRO, destaca a influência de Abdias na construção de políticas públicas para a população negra, que depois vem a se formalizar no Estatuto.

Nós do movimento negro não entendíamos que o Estatuto era algo novo, pois vinha desde o debate do Teatro Experimental e do trabalho realizado por Abdias do Nascimento, que já lançava propostas para diminuir a desigualdade entre negros e não negros na sociedade brasileira.

Ou seja, várias proposições que vão aparecer anteriormente à formalização do Estatuto, mas que vão ser sistematizadas no documento apresentado por Paulo Paim.

Segundo entrevista com Thiago Tobias, da EDUCAFRO, "houve várias legislações e defesas conceituais. Na verdade, existiam compêndios de lei para a questão racial. Quem organizou tudo foi Paulo Paim. Ele reúne tudo isso e transforma em Estatuto". Percebemos, então, que o formato de Estatuto aparece pela primeira vez no cenário político brasileiro a partir do desenho proposto por Paim, em diálogo constante com Edson Cardoso, que na época era seu assessor. $\mathrm{O}$ entrevistado ainda ressalta que Edson Cardoso foi muito importante para pautar o formato do Estatuto, pensando num desenho de um projeto que fosse propositivo, que mudasse o dia-a-dia do cidadão, já que essa era uma pauta do movimento negro.

Os autores do livro do INESC sobre o Estatuto da Igualdade Racial mostram que o processo de aprovação do projeto pode ser dividido em dois momentos. O primeiro que vai de junho de 2000 a novembro de 2005, conta com avanços e apoios parlamentares importantes a determinados artigos, especialmente o que se refere às propostas de ações afirmativas. $\mathrm{O}$ segundo momento, vai de dezembro de 2005 a junho de 2010, com uma trajetória oposta, em que se retiram várias propostas, diante da pressão da mídia, de cientistas sociais e parlamentares conservadores (SANTOS, SANTOS ; BERTÚLIO, 2011).

Vale ressaltar a mobilização feita em São Paulo para arrecadar assinaturas para a aprovação do estatuto. Nesse episódio, Thiago Tobias participou ativamente, conforme o relato:

A gente só acompanhou (o Estatuto) depois de um movimento que a gente
fez em São Paulo, que a gente liderou cem mil assinaturas para a aprovação
do Estatuto. A gente fez uma reunião com o presidente da Câmara que era
o Arlindo Chinaglia. A gente construiu um processo. A gente tinha uma
audiência pública no plenário do senado, da câmara federal. (...) e daí criou-se
uma comissão especial.

Ressalta-se a importância do diálogo entre o movimento negro e os parlamentares, especialmente nos processos de conferências e audiências públicas. Jerônimo Silva destaca que a inserção do movimento em espaços de participação social serviu de base para apresentar 
políticas públicas para os gestores. Segundo ele, "tinha uma parte do movimento que achava que podia criar políticas públicas sem ter diálogo com o Governo. Mas nós sempre primamos pela negociação". As propostas que saíam de espaços onde não havia presença de governos também acabavam chegando nas mãos dos gestores, seja pelos parlamentares envolvidos, seja por alguma liderança. Esse envolvimento entre sociedade civil (movimento negro) e Estado (parlamentares) propiciou a criação, na Câmara dos Deputados, da Comissão Geral para análise do Estatuto, coordenada por Arlindo Chinaglia.

Essas atividades são importantes para as histórias que vão sendo repassadas pelos ativistas no contexto da agregação de posicionamentos favoráveis ao que se propunha e na publicização da demanda, inclusive dentro do próprio movimento, ou seja, articulam-se narrativas que se repercutem e mobilizam mais pessoas. Thiago Tobias conta que vários militantes ainda não estavam familiarizados com o documento do Estatuto, mas que foi apresentado por Paulo Paim numa visita cidadã à Câmara de Deputados. Nas palavras de Thiago, "A gente visitou vários parlamentares, foi a primeira vez que na verdade eu vi pessoalmente o Paulo Paim e ele era presidente(sic) do Senado e apresentou o Estatuto pra nós lá da Educafro. Até então eu não tinha ouvido falar que a gente tinha um Estatuto".

Na Comissão Geral da Câmara, em 2007, a então ministra da SEPPIR, Matilde Ribeiro, apresenta a importância do diálogo sobre o Estatuto dentre os projetos que tramitavam na Casa. Para ela:

O Estatuto da Igualdade Racial, debatido de maneira bastante exaustiva ao longo dos anos nesta Casa, com a participação de movimentos sociais dos 4 cantos do Brasil, já aprovado no Senado em novembro de 2005, por meio da ação do Senador Paulo Paim, é uma peça fundamental para assegurar a continuidade das ações de Governo e afirmá-las como política de Estado, considerando a importância da normatização dessas ações na relação entre Estado, Governo Federal, Governos Estaduais e Governos Municipais. (CÂMARA DOS DEPUTADOS DO BRASIL, 2007, p. 7).

A fala da Ministra apresenta o posicionamento do Governo Federal com relação às propostas do Estatuto defendidas por Paulo Paim, mas apresenta também em outro momento a narrativa da denúncia contra a escravidão no país e as consequências desse processo na reprodução das desigualdades sociais. Esse argumento vai ser utilizado, conforme já destacamos anteriormente, como o motor da construção do documento e como agregador dos interesses da população negra. Para a ministra:

Não podemos cruzar os braços diante de injustiças, de invisibilidades e de casos históricos. A abolição deixou profundas marcas de desigualdades na 
nossa realidade social, política e econômica. Agora, compete a nós, por meio da adoção de políticas públicas efetivas, que devem ser um crescente na nossa história, construir as condições para a inclusão social e racial, bem como aprovar o Estatuto da Igualdade Racial (...) (CÂMARA DOS DEPUTADOS DO BRASIL, 2007, p. 8).

Destacamos, então, que o movimento negro emerge no espaço público como um novo ator político que questiona a história que é contada tradicionalmente e reconstrói a sua própria história a partir de estratégias discursivas, que afetam as narrativas e a interpretação da realidade social. Essas percepções e ideias se apresentam de diferentes maneiras na arena de disputas políticas no processo da aprovação do Estatuto, conforme veremos no item a seguir.

\section{CONSIDERAÇÕES FINAIS: MAS SÃO DISCURSOS E NARRATIVAS POLARIZADAS?}

Trabalhar com discursos e narrativas não tem sido uma vertente muito utilizada nos estudos sobre os movimentos sociais no Brasil. Apesar de haver uma vasta literatura internacional sobre essa discussão, acabamos utilizando nas nossas análises da atuação dos movimentos sociais as teorias da mobilização de recursos e oportunidades políticas, por um lado, e a teoria dos novos movimentos sociais, de outro. Esse texto teve como objetivo justamente enfocar brevemente a importância das narrativas como parte do processo estratégico dos movimentos sociais em especial, no que diz respeito à construção de proposições, elaboração de políticas públicas e sensibilização cognitiva dos agentes participantes das mudanças postuladas pelos movimentos sociais. Mostramos a importância do aspecto cultural na definição do movimento negro e a apropriação de símbolos para que a luta política se tornasse cada vez mais consolidada no cenário político. Tomando como objeto empírico a atuação do movimento negro e a aprovação do Estatuto da Igualdade Racial, buscamos trazer as ideias e narrativas contadas por lideranças do movimento negro em diferentes contextos históricos para perceber como foi possível a aprovação do documento. Mostramos que o movimento sempre pautou questões referentes ao racismo presente na sociedade brasileira e que teve apoio de vários legisladores no momento da entrada do Estatuto na agenda pública, além de um cenário político favorável às questões referentes às demandas da população negra no período que se inicia com o Governo Lula. A maior institucionalização do movimento "possibilitou a profissionalização e a especialização dos ativistas, bem como a formalização e a burocratização dos coletivos e das entidades” (RIOS, 2012; p.76). 
Apesar de haver entre o movimento diferenças de posicionamento com relação à aprovação do Estatuto - para uns era preciso aprovar naquele momento pois poderia não ter outras oportunidades, para outros era inadmissível apoiar um documento que retirava boa parte das pautas do movimento -, acreditamos que a dinâmica do jogo político se respalda no enfrentamento e concordâncias ao longo de todo o processo.

A variação de discursos em torno da aprovação do EIR modula de um lado, a alta expectativa quanto a um marco institucional que deveria impor políticas públicas de profundo graus de redistribuição baseada na ideia de reparações, e de outro lado, a busca pela necessidade de um marco institucional que autorizasse os entes federativos a subsidiar financeiramente as políticas públicas em geral, voltadas à população negra, baseadas na ideia de políticas de igualdade racial. A perspectiva que se consolidou na negociação foi a segunda, mais tímida em seu conceito, mas mais ampla em seu escopo, uma vez que versa sobre qualquer política de igualdade racial, mas isso ocorreu evitando confrontos que são fundamentais das relações de raça e classe no Brasil e da luta por direitos, prescindindo, inclusive do termo raça no próprio Estatuto da Igualdade Racial.

Por fim, ressaltamos que os encontros entre movimentos sociais e Estado apontam para questionamentos sobre as novas formas de elaborar políticas públicas no Brasil, alvo de estudos recentes na literatura dos movimentos sociais e que precisam de aprofundamentos, especialmente no que se refere ao papel das emoções evocadas no momento de contar as histórias para que os discursos e as ideias realmente consigam sensibilizar a população brasileira. Conforme ressalta Hédio da Silva Júnior, "Certamente tem uma parcela da população negra que não foi atingida pelo nosso discurso, mas é visível nas ruas que uma parcela significativa foi atingida pela ação política do movimento negro”. (ALBERTI; PEREIRA, 2007, p. 356).

\section{REFERÊNCIAS}

1. ABERS, Rebecca N; SERAFIM, Lizandra;TATAGIBA, Luciana. Repertórios de Interação Estado-Sociedade em um Estado Heterogêneo: A Experiência na Era Lula. DADOS Revista de Ciências Sociais, Rio de Janeiro, v. 57, n. 2, p. 325-357. 2014. Disponível em:https://www.scielo.br/scielo.php?pid=S0011-52582014000200003\&script=sci_ abstract\&tlng=pt. Acesso em: 01 mar. 2018.

2. ALBERTI, Verena; PEREIRA, Amilcar A. (Org.). Histórias do Movimento Negro no Brasil: Depoimentos ao CPDOC. Rio de Janeiro: Pallas/CPDOC-FGV, 2007. 
3. ARMSTRONG, Elizabeth; BERNSTEIN, Mary. Culture, powerandinstitutions: a multi-institutional politics approach to social movements. Sociological Theory. $\mathrm{n}$. 26, p.74-99. 2008. Disponível em: https://journals.sagepub.com/doi/10.1111/j.14679558.2008.00319.x. Acesso em: 01 mar. 2018.

4. BARCELOS, Luiz Cláudio. Mobilização racial no Brasil: uma revisão crítica. AfroÁsia. Salvador, n. 17, p. 187-210. 1996. Disponível em: https://portalseer.ufba.br/index. php/afroasia/article/view/20864. Acesso em: 23 fev. 2018.

5. BOURDIEU, Pierre. Coisas ditas. São Paulo: Brasiliense, 2004.

6. CÂMARA DOS DEPUTADOS DO BRASIL. Comissão Geral para o Estatuto da Igualdade Racial. Ata da 331 sessão. 26 nov. 2007. Disponível em: http://www2. camara.leg.br/atividade-legislativa/plenario/discursos/escrevendohistoria/125-anos-dalei-aurea/comissao-geral-para-debate-do-estatuto-da-igualdade-racial. Acesso em: 01 mar. 2018.

7. CARNEIRO, Lorena; LIMA, Wesley. A cultura negra: luta e resistência de um povo. Geledés - Instituto Mulher Negra, São Paulo, 2017. Disponível em: https://www. geledes.org.br/cultura-negra-luta-e-resistencia-de-um-povo/. Acesso em: 06 fev. 2019.

8. CARNEIRO, Sueli. Identidade feminina. Cadernos Geledés IV: Mulher Negra, São Paulo, 1993. Disponível em: https://www.geledes.org.br/cadernos-geledes/. Acesso em: 01 fev. 2018.

9. COLEY, Jonathan S. Narrative and Frame Alignment In Social Movements: Labor Problem Novel sand the 1929 Gastonia Strike. Social Movement Studies. v. 14, n. 1, p. 58-74. 2015. Disponível em: https://www.tandfonline.com/doi/abs/10.1080/14742837.2 013.873861. Acesso em: 06 fev. 2019.

10. GOMES, Angela de C. Prefácio. In: ALBERTI, Verena; PEREIRA, Amilcar A. (Org.). Histórias do movimento negro no Brasil. Depoimentos ao CPDOC. Rio de Janeiro: Pallas; CPDOC: FGV, 2007.

11. GOMES, Nilma L. O movimento negro no Brasil: ausências, emergências e a produção dos saberes. Revista Política \& Sociedade, vol.10, n. 18, pp.133-154, 2011. Disponível em: https://periodicos.ufsc.br/index.php/politica/article/view/2175-7984.2011v10n18p133. Acesso em: 01 mar. 2018.

12. GOODWIN, Jeef; JASPER, James M.; POLLETTA, Francesca. Passionate politics: emotions and social movements. Chicago: The University of Chicago Press, 2001.

13. HANCHARD, Michael George. Orfeu e o poder - movimento negro no Rio de Janeiro e São Paulo (1945 -1988). Rio de Janeiro: Editora UERJ, 2001.

14. JACCOUD, Luciana; BEGHIN, Nathalie. Desigualdades raciais no Brasil: um balanço da intervenção governamental. Brasília: IPEA, 2002. 
15. JIMENO, Myriam. El enfoque narrativo. In: JIMENO, M.; PABON, C.; VARELA, D.; DIAZ, I. (Ed.). Etnografias contemporâneas III: as narrativas na investigação antropológica. Univesidad Nacional de Colombia, 2016. p. 07-22.

16. KANE, Anne. Finding Emotion in Social Movement Processes: Irish Land Movement Metaphors and Narratives. In: GOODWIN, Jeef; JASPER, James M.; POLLETTA, Francesca. Passionate politics: emotions and social movements. Chicago: The University of Chicago Press, 2001.

17. KIngDON, John. Agendas, Alternatives, and Public Policies. 3a. ed. New York: Harper Collins, 2003.

18. LIMA, Márcia. Desigualdades raciais e políticas públicas: ações afirmativas no governo Lula. Novos Estudos. n. 87, 2010. Disponível em: https://www.scielo.br/scielo. php?script=sci_arttext\&pid=S0101-33002010000200005. Acesso em: 06 mar. 2019.

19. MORAIS, Danilo de Souza. Diferenças étnico-raciais e políticas de reconhecimento: perspectivas a partir do Conselho Nacional de Saúde e do Conselho Nacional de Educação. 2016. Tese (Doutorado em Sociologia). Programa de Pós-Graduação em Sociologia da Universidade Federal de São Carlos, Sorocaba.

20. MUNANGA, Kabengele. Kabengele apóia sanção do Estatuto da Igualdade Racial. SEPPIR, 01/07/2010. 2010. Disponível em: http:/www.seppir.gov.br/portal-antigo/ noticias/ultimas_noticias/2010/07/kabelengele-apoia-sancao-do-estatuto-da-igualdaderacial. Acesso em: 23 jan. 2018.

21. MUNDO AFRO. Estatuto é aprovado com as modificações. 2010. Disponível em: http://mundoafro.atarde.uol.com.br/tag/gilberto-leal/. Acesso em: 08 fev. 2018.

22. PASCHEL, Tiana S. Becoming black political subject. Movements and ethno-racial rights in Colombia and Brazil. Princenton University Press, 2016.

23. POLLETA, Francesca; SNOW, David; DELLA PORTA, Donatella; KLANDERMANS, Bert; MCADAM, Doug. The Wiley-Blackwell Encyclopedia of Social and Political Movements. Blackwell Publishing, 2013.

24. POLLETTA, Francesca. It was like a fever. Storytelling in protest and politics. Chicago: The University of Chicago Press, 2006.

25. POLLETTA, Francesca. Contending stories: narratives in social movements. Qualitative Sociology. v. 21, n. 4, p. 419-446. 1998. Disponível em: https://link.springer.com/ article/10.1023/A:1023332410633. Acesso em: 20 fev. 2018.

26. POLLETTA; Francesca.; GARDNER, Beth G. Narrative and Social movements. In: DELLA PORTA, D.; DIANI, M. The Oxford Handbook of Social Movements. Oxford Press, 2015.

27. RIOS, Flávia. O protesto negro no Brasil contemporâneo(1978-2010). Lua Nova: Revista 
de Cultura e Política. São Paulo, n. 85, p. 41-79. 2012. Disponível em: https://www. scielo.br/scielo.php?pid=S0102-64452012000100003\&script=sci_abstract\&tlng=pt. Acesso em: 20 fev. 2018.

28. ROLAND, Edna. Estatuto Racial: Canto a Palmares. Geledés - Instituto Mulher Negra, São Paulo, 2009. Disponível em: https://www.geledes.org.br/estatuto-racialcanto-palmares-por-edna-roland/. Acesso em: 24 jan. 2018

29. SANTOS, Sales Augusto dos; SANTOS, João Vitor Moreno dos; BERTÚLIO, Dora Lúcia. O processo de aprovação do Estatuto da Igualdade Racial. Lei n. ${ }^{\circ} 12.288$, de 20 de julho de 2010. Brasília, 2011. Brasília: INESC, 2011.

\section{Joana Tereza Vaz de Moura}

Doutorado em Ciência Política pela Universidade Federal do Rio Grande do Sul (2009) e Pós-doutorado em Sociologia pela New York University (2017). Professora do Departamento de Políticas Públicas do Centro de Ciências Humanas, Letras e Artes da Universidade Federal do Rio Grande do Norte. ID ORCID: https://orcid.org/0000-0001-9561-1063. E-mail: joanatereza@gmail.com. Colaboração: Pesquisa bibliográfica, Pesquisa empírica, Análise de dados. Redação.

\section{Paulo Cesar Ramos}

Doutorando em Sociologia na Universidade de São Paulo. ID ORCID: https://orcid.org/00000001-9283-3592. E-mail: ramos.pauloc@gmail.com. Colaboração: Pesquisa empírica. Análise de Dados, Redação. 